ISSN 1997-5902

\title{
Molecular characterization of trypanosomes isolated from naturally infected cattle in the "Pays Lobi" of Côte d'ivoire
}

\author{
Koffi M. 1,2, Kouadio KI ${ }^{3}$, Sokouri D.P. ${ }^{3 *}$, Wognin M.T. ${ }^{3}$, N'Guetta ASP 3 \\ 1 Université Jean Lorougnon Guédé, UFR Environnement, Laboratoire des Interactions Hôte-Microorganisme- \\ Environnement et Evolution, BP 150 Daloa, Côte d'Ivoire. \\ ${ }^{2}$ Centre Suisse de Recherches Scientifiques en Côte d'Ivoire, Département Environnement et Santé, 01 BP 1303, \\ Abidjan, Côte d'Ivoire. \\ 3 Université Félix Houphouet Boigny, UFR Biosciences / Laboratoire de Génétique, 22 BP 582 Abidjan 22, Côte \\ d'Ivoire \\ *Corresponding author, E-mail: didiersokouri@yahoo.fr
}

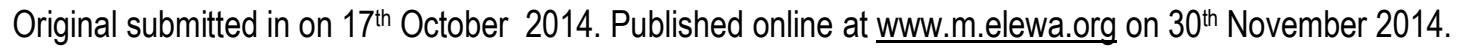
http://dx.doi.org/10.4314/jab.v83i1.10

\begin{abstract}
Objectives: this study aimed to investigate the prevalence of bovine trypanosomosis in the "Pays Lobi" of Côte d'Ivoire where a lot of trypanosusceptible zebu cattle are now found.

Methodology and Results: Blood samples were collected from 200 male and female cattle sampled in five villages from the department of Bouna. PCR technique was used for the diagnosis of trypanosomes. Out of the 200 animals examined, 41 were infected with trypanosomes, representing an infection prevalence of $20.5 \%$. The specific diagnosis revealed prevalence rates of $2.5 \%, 3 \%, 5 \%, 10 \%$ for $T$. congolense "Savannah", T. conglense "Forest", T. vivax and T. brucei, respectively. Three mixed infections were found involving $T$ congolense "Savannah" and T. brucei, $T$. congolense "Forest" and T. vivax, $T$. vivax and $T$. brucei.

Conclusions and applications of findings: The outcome of this study has shown that more attention is needed in controlling trypanosome infection in the "Pays Lobi". Indeed, better understanding of prevalence of sub- clinical infection could help with efforts to control the disease and population-based screening of both animal and insect vectors.
\end{abstract}

Key words: Prevalence, Trypanosomes, trypanosusceptible, zebu; "Pays Lobi"

\section{INTRODUCTION}

In sub-Saharan Africa, diseases transmitted by tsetse flies are a problem for both animal and human health. Animal African Trypanosomosis (AAT) is a vector-borne disease found in tropical regions of Africa (Euzeby 1986). The tsetse fly transmitted trypanosomes, Trypanosoma brucei, $T$. congolense and $T$. Vivax, specific to cattle and other ruminants (Alfredo, 2004; Jay, 2008). Human African trypanosomiasis (HAT), also known as sleeping sickness is an endemic parasitic disease caused by Trypanosoma brucei sl.

In Africa, AAT is rampant in 37 countries of subSaharan region, an area of approximately 10 million km2 (Trail et al. 1985; Erkelens et al., 
2000). AAT remains a major pathological constraint for livestock development in subSaharan Africa, in areas that have high forage and agricultural potentials (Panin \& Mahabile, 1997). The parasitic disease altered cattle distribution in the region and in addition to causing widespread disease. This disease created local overstocking restricted to Africa where it have been responsible for the exclusion of livestock from large areas of land which are potentially capable of problems in tsetse-free grazing areas. Moreover, ATT enforced nomadism on breeding herds and economic loss in cattle along cattle trade routes in West Africa (Rogers et al., 1996; Wilson et al., 1997). The direct and indirect losses of currencies linked to this pathology are estimated at about 4.5 billion dollars (Mattioli et al., 2004). In tsetse-infested areas, the deficit in meat production is estimated at $30 \%$, and that of milk production to $40 \%$. Furthermore, a farmer breeds about 2 fold less draught animals and cultivated 3 fold less area (Swallow 1998). In Côte d'Ivoire, except for the forest area $(4.3 \%$ of livestock) where environmental conditions are a limiting factor for the development of animal husbandry, pre-forest (central) region ( $17.4 \%$ of national herd) and the northern region ( $78.3 \%$ of national herd) appear as livestock regions. However, in some parts of these regions, the prevalence of AAT may reach $25 \%$ when there is no control activity. This prevalence is detrimental to farms and animals productivity in this region where breeders from neighbouring sahelian countries and their zebu cattle tend to settle. This is the case of "Pays Lobi" that was literally invaded by zebu cattle. Yet this area of the Northern Region of Côte d'Ivoire has long been

\section{MATERIAL AND METHODS}

Study Area: This study was conducted in five (05) farms selected in different villages of the department of Bouna : The village of Kopengué located at $32 \mathrm{~km}$ in the west; Tamé-Koulda at $30 \mathrm{~km}$ in the north, Niandégué and Bromakoté located at $07 \mathrm{~km}$ in the northwest and a camp located near the aerodrome at 4 $\mathrm{km}$ in the south of Bouna (Figure 1). Farms were selected by agents of the Department of Animal Production and Fisheries Resources, according to the different geographical areas of the study zone. This considered the cradle of trypanotolerant Baoule breed. Indeed, this region has long been closed to entry of foreign cattle breeds. Nowadays, the cattle herd composition of "Pays Lobi" is strongly influenced by the presence of zebu cattle trypanosusceptible. Indeed, most of the farms in this area are characterized by the presence of local breed (Baoulé), zebu and Méré (animals from crosses between zebu and Baoulé cattle). Furthermore, farmers breed these trypanosusceptible zebu cattle under high trypanocide drug coverage. Nevertheless the wide spread use and the misuse of drug has contributed to the development of dru resistance in the population T. conglense parasites (Codjia et al., 1993; Afework et al., 2000). Therefore, it appears necessary to assess the trypanosome risk on cattle farms in this area, where many trypanosusceptible cattle (zebu) are now found. The use of traditional microscopic such as determination of parasite mobility and morphology is sufficient to distinguish the trypanosome species in the mammalian host. However, this method is not accurate enough to provide diagnosis, since many-mixed infections occur in natural conditions (Solano et al, 1995, 1996). The molecular biology method has overcome the limits of sensitivity and specificity of the old methods (Morlais et al, 1998). The polymerase chain reaction (PCR) has been developed to facilitate the detection of many types of parasite (De Bruijn et al., 1993; Laserson et al., 1994), including trypanosomes (Masiga et al., 1992; Majiwa et al., 1994; McNamara et al., 1995). Therefore, this study aims to detect and identify trypanosome infections in cattle from "Pays Lobi" of Côte d'Ivoire, using PCR technique.

selection was based on the following criteria: (i) accessibility of the park, (ii) availability of breeder and (iii) presence of greater than 50 individuals in the herd. The department of Bouna, is located in the north-east of Côte d'lvoire, near the border with Ghana and Burkina Faso. With an area of $38,000 \mathrm{~km} 2$, the department of Bouna is one of the gateways to the Comoé National Park. The terrain is flat. However, there are some mountains whose heights, ranging from 500 to 600 meters, which break in places the uniformity 


\section{Koffi et al. J. Appl. Biosci. 2014 Molecular characterization of trypanosomes isolated from naturally infected cattle in the "Pays Lobi" of Côte d'Ivoire}

of the landscape. The climate is a sub-Sudanese one, and it has four seasons, two rainy seasons from March to June and September to October, respectively. These are interspersed with two dry seasons, which start from November to February and July to August, respectively. Annual rainfall varies between 1100 and $1200 \mathrm{~mm}$ with an average temperature of $28^{\circ} \mathrm{C}$. The vegetation consists of Sudano-Guinean savannah woodlands, wooded savannas and woodlands. Under the effect of socio-economic activities, the vegetation is increasingly dominated by shrubs and herbs. The drainage system consists of two main rivers that are Comoe and Black Volta. Agriculture and animal husbandry are the main activities of rural people. Indeed, cattle and small ruminants are the second pillar of the region's economy.

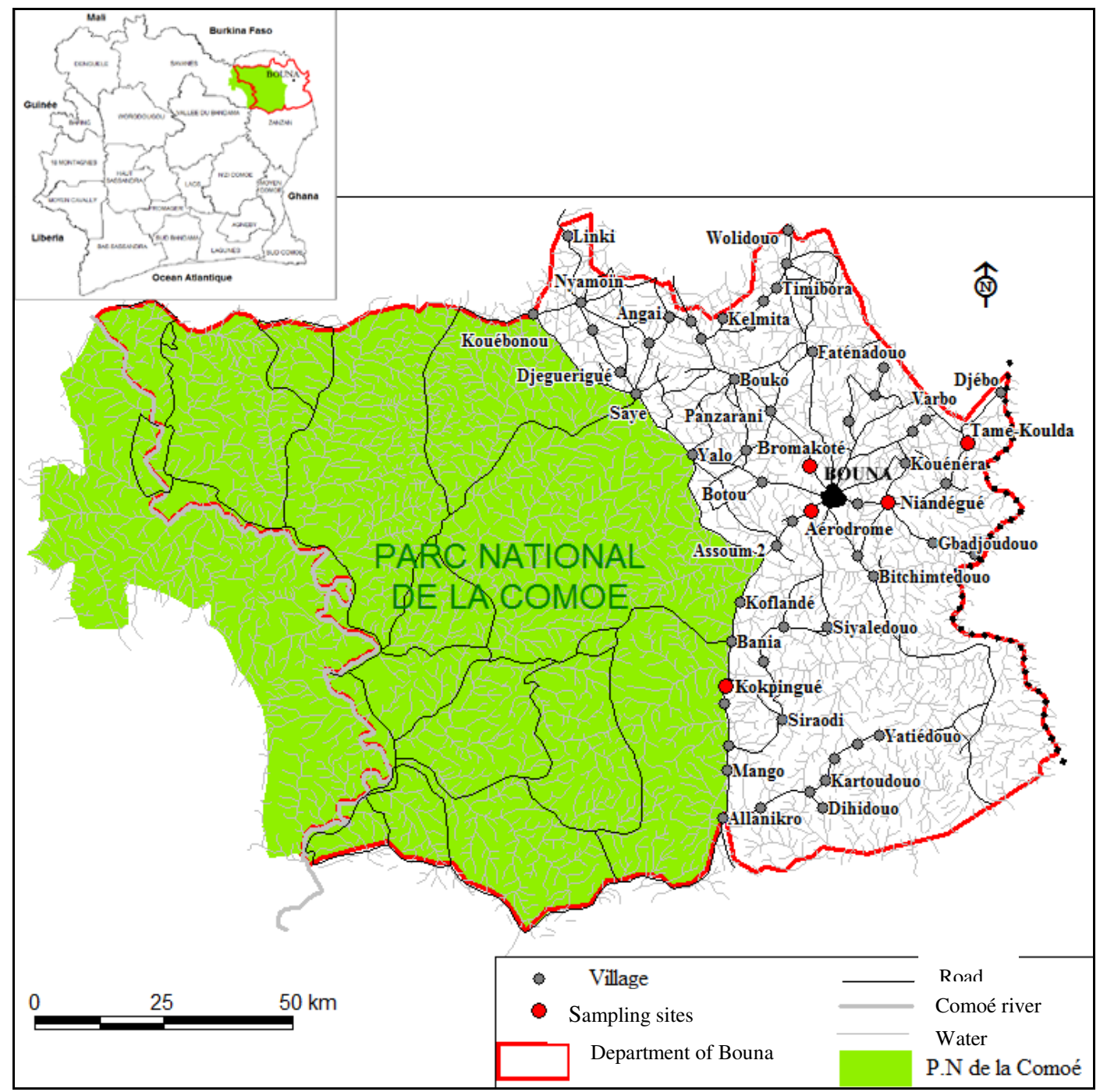

Figure 1: geographical distribution of sampling sites

\section{Methods}

Sampling: In each farm visited, 40 male and female cattle aged more than a year, were sampled taking into account all the breeds present in the herd. In each farm, the choice of animals was done randomly. From each animal sampled, $5 \mathrm{ml}$ of blood was collected from the jugular vein into a "vacutainer" EDTA tube (ethylene diamine tetra acetic acid), and stored in ice. Two (2) aliquots of $1 \mathrm{ml}$ were carried out from collected blood. Aliquots were kept on ice in the field before being frozen in the Laboratory for molecular analyzes. Each sampled animal was identified by a code to find the 


\section{Koffi et al. J. Appl. Biosci. 2014 Molecular characterization of trypanosomes isolated from naturally infected cattle in the "Pays Lobi" of Côte d'Ivoire}

name of the village, livestock and the serial number of this animal. The same code was carried over the tubes containing the different blood samples. In addition, some information about the body condition of animals sampled was collected.

PCR technique: Genomic DNA was extracted from blood samples collected according to Phenol chloroform method (Maymonna, 1998). PCR technique was applied to determine the presence of genes of different species of trypanosomes. Amplification reaction was performed in a final volume of $50 \mu \mathrm{l}$ containing $10 \mathrm{mM}$ of Tris-HCL pH 8.3, $50 \mathrm{mM}$ of $\mathrm{KCl}, 3$ $\mathrm{mM}$ of $\mathrm{MgCl} 23,200 \mathrm{ml}$ of each deoxynucleotide triphosphates (dATP, dGTP, dCTP and dTTP), 20 pmol of each primer, 5 units of Taq DNA polymerase amp (5') and $5 \mu$ l of extracted DNA (diluted 1/10 or 1/30). The thermal cycler (BIO RAD T100 Thermal cycler) was programmed as follows: an initial denaturation step of 3 min at $94{ }^{\circ} \mathrm{C}$ followed by 30 times repeated cycling step comprising a denaturation phase of $30 \mathrm{sec}$ at $94^{\circ} \mathrm{C}$, a phase of fixing of the primers $30 \mathrm{sec}$ at $60^{\circ} \mathrm{C}$ and an elongation phase at $72^{\circ} \mathrm{C} 1 \mathrm{~min}$ and finally a step of 10 min to a final $72{ }^{\circ} \mathrm{C}$ extension. The amplification products were subjected to electrophoresis on agarose gel for visualization. The amplification products migrate according to their size. The agarose gel was prepared at $2 \%$ in a $0.5 \times$ TBE buffer and placed in a tank of electrophoretic migration. In each well of the gel produced using a comb, $7 \mu$ l of each amplification product and a molecular weight marker product (Table 1) were deposited. Then, the generator was powered $(100 \mathrm{~V})$. Electrophoretic migration takes about $30 \mathrm{~min}$. After electrophoresis, the gel is then placed in a tank containing a solution of ethidium bromide $(4 \mu \mathrm{g} / \mathrm{ml})$ for $20 \mathrm{~min}$. After rinsing, the gel is placed on a UV transilluminator and photographed to be viewed. The nucleotide sequences of the primers used for PCR are shown in Table 1.

Table 1: Primers used for PCR amplification of trypanosome

\begin{tabular}{lllll}
\hline Speficity & Code & Primer sequence & AP(1) & Reference \\
\hline$T$ congolense & TCS $_{1}$ & 5'CGAGAACGGGCACTTTGCGA3' & \multirow{2}{*}{316} & Masiga et al. (1992) \\
(savannah) & TCS $_{2}$ & 5'ACACGCCCTAAAGAACAGC3' & & \\
$T$ congolense & TCF $_{1}$ & 5'GGACACGCCAGAAGGTACTT3' & \multirow{2}{*}{350} & Masiga et al. (1992) \\
(forest) & TCF $_{2}$ & 5'CAACCTAAACCACGCTCTTG3' & & \\
$T$ T vivax & TVW $_{1}$ & 5'CTGAGTGCTCCATGTGCAAC3' & \multirow{2}{*}{150} & Masiga et al. (1992) \\
& TVW $_{2}$ & 5'AGTCCAACCACAAGACCACC3' & & \\
T brucei & TBR1 & 5'CGAATGAATAACAATGCGCAGT3' & \multirow{2}{*}{164} & Masiga et al. (1992) \\
& TBR2 & 5'AGAACCATTTATTAGCTTTGTTGC3' & &
\end{tabular}

(1) Expected size of the amplification product (Bp).

Data analysis: Data obtained were recorded in Excel to produce descriptive statistics. These descriptive statistics was employed in analyzing the data. The prevalence rates among localities, type of cattle, and sex of the animals were expressed as percentage of the total number of animal sampled. Chi square test

\section{RESULTS}

Overall prevalence: The examination by PCR for the presence of at least one of four species of trypanosomes permitted to obtain an average parasitological prevalence of $20.5 \%$ (41/200). No significant difference of infection $(p>0.05)$ was observed among the sampling sites. However, the highest infection was observed in the locality of Kopengué with a prevalence rate of $32.5 \%$ (13/40). The lowest infection was observed in the sampling site near the aerodrome with a prevalence rate of $7.5 \%$ (Table 2). Out of the 200 animals sampled in this study was used to evaluate association between the prevalence of infection and locality, breed and sex of the cattle studied. A P value of $P<0.05$ was considered significant. These analyzes were performed using STATA 9.0

35 were Méré cattle and 165 zebu cattle. Of the 33 Méré cattle examined, 8 were infected with a prevalence rate of $22.86 \%$. The prevalence observed in zebu cattle was $20 \%$ (33/165). No significant difference of infection $(p>0.05)$ was observed between these two types of cattle. A total of 177 female were sampled in this study and in total and $20.33 \%$ of them were positive for AAT (36/177). Out of the 23 male examined, 5 were infected with a prevalence rate of $21.74 \%$. No significant difference $(p>0.05)$ was observed between male and female. 


\section{Koffi et al. J. Appl. Biosci. 2014 Molecular characterization of trypanosomes isolated from naturally}

infected cattle in the "Pays Lobi" of Côte d'Ivoire

Table 2: Prevalence of trypanosomes depending on sampling sites

\begin{tabular}{lccccr}
\hline Sampling site & Sample size & Infected animals & Prevalence $(\%)$ & X2 & P. value \\
\hline Kopengué & 40 & 9 & 22.5 & 6.57 & 0.160 \\
Tamé-Koulda & 40 & 7 & 17.5 & & \\
Niandégué & 40 & 9 & 22.5 & & \\
Bromakoté & 40 & 13 & 32.5 & & \\
Aerodrome & 40 & 3 & 7.5 & \\
\hline Total & 200 & 41 & $20.5^{*}$ & & \\
\hline
\end{tabular}

*Overall prevalence

\section{Specific diagnosis}

Diagnosis of T. congolense "Savanah": PCR technique for the specific diagnosis of $T$. congolense "savannah" in the five sampling sites permitted to obtain an overall prevalence of $2.5 \%$. A heterogeneity in prevalence was observed among the five (05) study sites, although there was no significant difference of infection $(p>0.05)$ with $T$. congolense "Savannah" between these sites. Infection with the parasite was observed in two sites only, in the village of Bromakoté, with a prevalence of $7.5 \%$ and in Tamé-Koulda where a prevalence of $5 \%$ was observed. However, there was no parasitic infection in the three other sites: Kopengué, Niandégué and Aerodrome (Table 3).

Diagnosis of T. congolense "Forest": From the total of 200 animals examined for AAT, 6 were positive for $T$. congolense "Forest". The comparison of prevalence of the 5 sampling sites showed that there is no significant difference of infection ( $p>0.05$ ) between them. However, infection with this parasite was observed in two sites; Kopengue and Tamé-Koulda with the same prevalence, $7.5 \%$, while no animals was infected with this parasite in the three other sampling sites (Table 3).

Table 3: Prevalence of T. congolense "Savanah" and T. congolense "Forest"

\begin{tabular}{|c|c|c|c|c|c|c|c|c|c|c|}
\hline & \multicolumn{5}{|c|}{ T. congolense "Savanah" } & \multicolumn{5}{|c|}{ T. congolense "Forest" } \\
\hline Localities & $\mathrm{Nt}$ & $\mathrm{Ni}$ & Prev. (\%) & $X^{2}$ & $P$ & $\mathrm{Nt}$ & $\mathrm{Ni}$ & Prev. (\%) & $x^{2}$ & $P$ \\
\hline Kopengué & 40 & 0 & 0 & 8.2 & 0.003 & 40 & 3 & 7.5 & 9.28 & 0.06 \\
\hline Tamé (1) & 40 & 2 & 5 & & & 40 & 3 & 7.5 & & \\
\hline Niandégué & 40 & 0 & 0 & & & 40 & 0 & 0 & & \\
\hline Bromakoté & 40 & 3 & 7.5 & & & 40 & 0 & 0 & & \\
\hline Aerodrome & 40 & 0 & 0 & & & 40 & 0 & 0 & & \\
\hline Total & 200 & 5 & $2.5^{(2)}$ & & & 200 & 6 & $3^{(2)}$ & & \\
\hline
\end{tabular}

Nt : Sample size ; Ni : Number of animals infected, Prev. : Prevalence, P: P-value

(1) Tamé-Koulda

(2) Overall prevalence

Diagnosis of T. vivax: Molecular analysis of the 200 animals for the specific diagnosis of $T$. vivax yielded an average prevalence rate of $5 \%$. The prevalence rate of $15 \%$ observed in the locality of Kopengue was significantly higher than that obtained in the other sites. However, no infection with $T$. vivax was observed in the locality of Niandégué (Table 4).

Diagnosis of T. bucei: Out of the total of 200 animals examined, 20 were infected with $T$. bucei, with a prevalence rate of $10 \%$. The comparison of prevalence rate from the different sampling sites through the Khisquare test showed a very highly significant difference $(p<0.001)$ between these sites. No infection was observed in the village of Kopengué and Tamé-Koulda. However, in Niandégué and Bromakoté, a prevalence rate of $22.5 \%$ was observed; 9 animals out of 40 were infected with $T$. bucei (Table 4). 
Koffi et al. J. Appl. Biosci. 2014 Molecular characterization of trypanosomes isolated from naturally infected cattle in the "Pays Lobi" of Côte d'Ivoire

Table 4: Prevalence of $T$. vivax and $T$ brucei

\begin{tabular}{|c|c|c|c|c|c|c|c|c|c|c|}
\hline & \multicolumn{5}{|c|}{ T. vivax } & \multicolumn{5}{|c|}{ T. brucei } \\
\hline Localities & $\mathrm{Nt}$ & $\mathrm{Ni}$ & Prev. (\%) & $X^{2}$ & $P$ & $\mathrm{Nt}$ & $\mathrm{Ni}$ & Prev. (\%) & $\mathrm{X}^{2}$ & $P$ \\
\hline Kopengué & 40 & 6 & 15 & 11.6 & 0.02 & 40 & 0 & 0 & 23.89 & 0.0008 \\
\hline Tamé (1) & 40 & 2 & 5 & & & 40 & 0 & 0 & & \\
\hline Niandégué & 40 & 0 & 0 & & & 40 & 9 & 22.5 & & \\
\hline Bromakoté & 40 & 1 & 2.5 & & & 40 & 9 & 22.5 & & \\
\hline Aerodrome & 40 & 1 & 2.5 & & & 40 & 2 & 5 & & \\
\hline Total & 200 & 10 & $5^{(2)}$ & & & 200 & 20 & $10^{(2)}$ & & \\
\hline
\end{tabular}

$\mathrm{Nt}$ : Sample size ; Ni : Number of animals infected, Prev. : Prevalence, P: P-value

(1) Tamé-Koulda

(2) Overall prevalence

Types of infection: Among the 41 cases of infection detected by PCR technique out of the 200 samples of this study, 37 cases $(90.24 \%)$ were mono-infections. Four (4) cases of mixed infections were observed. There were two cases of mixed infection involving $T$

\section{DISCUSSION}

The prevalence rate of bovine trypanosomosis of 20.5 $\%$ obtained in this study is higher than the $3.9 \%$ previously reported in grazing cattle in Ogbomoso, Oyo State (Ameen et al., 2008), 4.69\% previously reported in the Oyo State in Nigeria (Fasanmi et al., 2014) and $7.81 \%$ previously reported in Woliso Woreda, Ethiopia (Gebreyohannes \& Legesse, 2014). However, the $46.8 \%$ of bovine trypanosomosis rate reported on the Jos Plateau, Nigeria are higher than what was found in this study (Majekodunmi et al., 2013). This difference could be due to the difference between the number of sampling sites and the sample size. In effect, in this study a total of 200 animals were sampled in five villages, while Majekodunmi et al. (2013) have examined 7,143 individual cattle sampled in 30 villages. Furthermore, the absence of a significant difference of infection between the five sampling suggests no discriminatory presence of trypanosomes in all the study area. Moreover, the lowest prevalence rate of trypanosomosis observed in site near aerodrome could be attributed either to (i) a better implementation of preventive and curative trypanocidal treatments in the herds by farmers, (ii) good knowledge of the grazing course by the herdsmen who drive the animals, or (iii) the low level of infestation of the route by the flies. For prevalence depending on type of cattle, no significant difference of infection $(p>0.05)$ was observed between zebu and Méré cattle. However, the observed imbalance in sample sizes of cattle could not allow objective comparisons between these types of cattle. congolense Savannah and T. brucei, one case of mixed infection involving $T$. congolense Forest and $T$. vivax, one case of mixed infection involving $T$. vivax and $T$. brucei.

The sample of 200 cattle of this study consists of 165 zebu cattle, against only 35 Méré cattle. In effect, studies in northern Côte d'lvoire during the 1980s and analyzing the degree of infection in different genotypes showed that zebu cattle showed infection levels much higher than those of all other genetic, Baoulé, N'Dama and zebu crossbred with (Camus, 1981). Indeed, some studies have provided an exacerbation, the situation of trypanosomiasis with increased blood circulation. In effect, Zebu in farms villagers consist of bullfighting in N'Dama Baoulé (Camus et al., 1981; Sokouri et al., 2009; Bocoum et al., 2012). The result of this study showed that sex prevalence of bovine trypanosomosis was not significantly different between male and female animals. However, this result could not objective because of the great difference between the male sample size (23 individuals) and the female sample size (177 individuals). However, Fasanmi et al. (2014) who examined 121 female cattle and 199 male, also reported no significant difference in the infection prevalence of male and female animals. Sex dimorphism in trypanosomosis has been previously reported (Abenga et al., 2004; Agu et al., 1990, Agu \& Amadi, 2001). This result is also in agreement with those reported by Sam-Wobo et al. (2010). The specific diagnosis allowed the following prevalence; $2.5 \%$ for $T$. congolense "Savannah" and $3 \%$ for $T$. congolense "Forest", $5 \%$ for $T$. vivax and $10 \%$ for T brucei. Thus, the results of this study showed the prevalence of three trypanosomes, $T$. congolense, $T$. vivax and $T$ brucei, 


\section{Koffi et al. J. Appl. Biosci. 2014 Molecular characterization of trypanosomes isolated from naturally infected cattle in the "Pays Lobi" of Côte d'Ivoire}

infecting mainly livestock in this region. The prevalence of $T$ Congolense infection in this study is lower than that $(27.7 \%)$ reported on the Jos Plateau, Nigeria (Majekodunmi et al., 2013). However, this prevalence is higher that $(0.005 \%)$ reported in Ethiopia by Gebreyohannes \& Legesse (2014). These authors assert that the presence of low prevalence of $T$. conglense is associated with low tsetse infested area. $T$. conglense may enter from endemic area due to animal movement. The prevalence of $T$. vivax infection reported in this study is comparatively lower than those reported on T. vivax epizootiology in Nigeria (Agu \& Amadi, 2001; Ameen et al., 2008; Fasanmi et al., 2014). According to Fasanmi et al (2014), the higher

\section{CONCLUSION}

This study assessed the trypanosome risk and diagnoses various specific species in the "Pays Lobi" of Côte d'Ivoire, by using the PCR technique. The average prevalence of infection, revealed by molecular analysis, was $20.5 \%$. Three species of trypanosomes were found in the study area; $T$. congolense (the Savannah type with a prevalence rate of $2.5 \%$ and the Forest type with $3 \%$ ), $T$. vivax with a prevalence rate of $5 \%$ and $T$ brucei with a prevalence rate of $10 \%$. The prevalence of $T$. vivax observed in Nigeria may be connected with its molecular biology, which may have played a role in conferring it with resistance against both drugs and host defence. This could be the cause of the superiority of $T$. brucei on the other species, with a prevalence rate of $10 \%$. Moreover, both tsetse species: G. tachinoides and G. p. palpalis which are able to transmit $T$. brucei (Majekodunmi, 2006) are abundant in the study area and they transmit this species at a higher frequency. The results of this study about mixed infection involving $T$ congolense Savannah and $T$. brucei, T. congolense Forest and T. vivax, are also reported in Burkina Faso by Solano et al. (1997).

outcome of this study has shown that more attention is needed in controlling trypanosome infection in the "Pays Lobi". Therefore, it appears necessary to investigate the prevalence of bovine trypanosomosis throughout all the "Pays Lobi". Thus, it would be interesting to extend this study to other areas of this region. It also seems necessary to (i) characterize the different species of flies that are present in the region and (ii) assess drug resistance of trypanosomes.

\section{ACKNOWLEDGEMENTS}

The authors would like to thank the "Union Economique et Monétaire Ouest Africaine (UEMOA)" for funding this project trough the "Projet d'Appui à l'Enseignement Supérieur (PAES)".

\section{REFERENCES}

Afowork y, Clauson PH, Abebe G, Tilahun G, Mahaltiz D, 2000. Drug resistances Tryponosoma Conglense population in village cattle of Mekele district North West Ethiopia. Acta. Trop., 76: 231-238.

Alfredo M, 2004. A history of epidemiology: Methods and concepts. Birkhouse Publishers, UK. 93 pp.

Ameen SA, Joshua RA, Adedeji OS, Raheem AK, Akingbade AA, Leigh OO, 2008. Preliminary studies on prevalence of Ruminant trypanosomosis in Ogbomoso area of Oyo State, Nigeria. Middle East Journal of Scientific Research, 3 (4): 214-218.

Bocoum Zakaria, Diarra Modibo, Maiga Hamidou M, Sanogo Youssouf, Sylla Mahamadou S.M, Diall Oumar, 2012. Prevalence in the Bovine Trypanosomiasis Kadiolo Circle. J Community Med Health Educ, 2:9. http://dx.doi.org/10.4172/2161-0711.1000183
Camus E, 1981. Epidemiology and clinical incidence of bovine trypanosomiasis in the North of the Ivory Coast. Rev Elev Med Vet Pays Trop 34: 289-295.

Camus E, Landais E, Poivey JP, 1981. Genetic structure of sedentary cattle of the northern Ivory Coast. Future prospects as a function of crossbreeding of zebu stock. Rev Elev Med Vet Pays Trop 34: 187-198.

Codjia V, Mulata W, Majiwa PAO, Leake SGA, Rowlands Gj, Authie ED, Leteren GDM, Pregerine AS, 1993. South West Ethiopia 3 occurrence of population of Tryponasoma conglense is resistances to dimnizine, Iso methamedium and homidium. Acta. Trop., 53: 151-163.

De Bruijn MHL, Labrada LA, Smyth AJ, Sautrich C, Barker DC, 1993. A comparative study of diagnosis by the polymerase chain reaction and by current clinical methods using biopsies 
from colombian patients with suspected leishmaniasis. Trop. Med. Parasitol., 44: 201207.

Erkelers AM, Duinger RH, Bedane B, slingenbergh JHW, Wint W, 2000. Selection of priority area for TseTse control in Africa decision tool using Gis in Dedessa Valley, Ethiopia as a pilot study in animal Tryponosomiasis, diagnosis and epidemiology of FAO/IAEA Coordinate Research program on the use of Immuno assay method For Improved Diagnosis of Trypanosomiasis \& monitoring TseTse \& Trypanosomiasis control programs international Atomic Energy Agen.Veinna, Austria.

Euzeby J, 1986. Protozoologie médicale comparée, 1: Généralités - Sarcomastigophores (Flagellés, Rhizopodes) - Ciliés. Collections Marcel Mérieux, Lyon. 463 pp.

Fasanmi OG, Okoroafor UP, Nwufoh OC, BukolaOladele OM, Ajibola ES, 2014. Survey for trypanosoma species in cattle from three farms in Iddo Local Government Area, Oyo State. Sokoto Journal of Veterinary Sciences 12 (1): 57-61.

Gebreyohannes M and Legesse F, 2014. Epidemiological Study of Bovine Trypanosomiasis in Woliso Woreda, Ethiopia. J Anim Sci Adv, 4 (5): 833-838.

Laserson KF, Petralanda I, Hamlin, DM, Almera R, Fuentes M, Carrasquel A, Barker RH, 1994. Use for the polymerase chain reaction to directly detect malaria parasites in blood samples from the Venezuelan Amazon. Am. J. Trop. Med. Hyg, 50: 169-180.

Mahama C, Desquesnes M, Diam L, Losson B, De Deken R, Geerts S, 2004. A cross-sectional epidemiological survey of bovine trypanosomosis and its vectors in the Savelugu and West Mamprusi districts of northern Ghana. Vet. Parasitology, 122: 1-13.

Majekodunmi AO, 2006. Multidisciplinary investigation of the trypanosome infection status and spatial and temporal distribution of tsetse flies on the Jos Plateau using entomological, molecular and geographical methods. MSc thesis. London: London School of Hygiene and Tropical Medicine, Department of Infectious and Tropical Disease.

Majekodunmi Ayodele O, Fajinmi Akinyemi, Dongkum Charles, Picozzi Kim, Thrusfield Michael V,
Welburn Susan C, 2013. A longitudinal survey of African animal trypanosomiasis in domestic cattle on the Jos Plateau, Nigeria: prevalence, distribution and risk factors. Parasites \& Vectors, 6:239. http://www.parasitesandvectors.com/content/6/ $1 / 239$

Majiwa PAO, Thatthi R, Moloo SK, Nyeko, JHP, Otieno LH, Maloo S, 1994. Detection of trypanosome infections in the saliva of tsetse flies and buffycoat samples from antigenaemic but aparasitaemic cattle. Parasitology 108: 313322.

Masiga k, Smith A, Hayes P, Bromidge T, Gibson W, 1992. Sensitive detection of Trypanosomes in tsetse flies by DNA amplification. International Journal for Parasitology: 22: 909-918.

Mattioli RC, Feldmann G, Hendrickx W, Wint J, Jannin J. 2004. Tsetse and Trypanosomiasis intervention policies supporting sustainable animal- agricultural development. Food Agr Environ 2: 310-314.

Maymonna Sy NDIR. 1998. Recherche de diversité génétique au sein d'une population Stemphylium solani Weber au Sénégal. Rapport de stage. I'ORSTOM - Montpellier, France. $66 \mathrm{p}$.

McNamara JJ, Laveissiere C, Masiga DK, 1995. Multiple trypanosome infections in wild tsetse in Côte d'Ivoire detected by PCR analysis and DNA probes. Acta Trop: 59, 85-92.

Morlais I,. Grebaut P,. Bodo J.M, Djoha S,. Cuny G, Herder S, 1998. Detection and identification of trypanosomes by polymerase chain reaction in wild tsetse flies in Cameroon. Acta Tropica , 70:109-117

Panin A and Mahabile M, 1997. Profitability and household income contribution of small ruminants to small scale farmers in Botswana. Small Ruminant Resources, 25 (1): 9-15.

Reifenberg JM, Solano P, Duvallet G, Cuisance D, Simporé J, Cuny G, 1997. Molecular characterization of trypanosomes isolates from naturally infected domestic animals in Burkina Faso. Veterinary Parasitology, 71: 251-262

Rogers DJ, Hay S, Packer MJ, 1996. Predicting the distribution of tsetse flies in West Africa using Temeral fourier processed meteorological satellite data. Annals of Tropical Medicine and Parasitology, 90 (3): 225-241. 
Sam-Wobo SO, Igenezoa AJ, Idowu OA, Otesile EB, Ekpo UF \& Kehinde OO, 2010. Bovine trypanosomiasis and its impact on cattle in derived Savannah areas of Ogun state, Nigeria. Journal of Public health and Epidemiology, 2 (3): 43-47.

Schares $G$ and Melhitz D, 1996. Sleeping sickness in Zaire: a nested polymerase chain reaction improve the identification of Trypanosoma (Trypanozoon) brucei gambiense by specific kinetoplast DNA probes. Tropical Medecine and International Health, 1: 59-70.

Sokouri DP, Yapi-Gnaoré CV, N'Guetta, ASP, Loukou $\mathrm{NE}$, Kouao BJ, Touré G, Sangaré A, Kouassi $A, 2009$. Utilisation et gestation des races taurines locales sous la pression des croisements avec les zébus dans les régions Centre et Nord de la Côte d'lvoire. Journal of Animal \& Plant Sciences, 5 (2): 456-465.

Solano P, Argiro L, Reifenberg JM, Yao Y, Duvallet G, 1995. Field application of the polymerase chain reaction (PCR) to the detection and characterization of trypanosomes in Glossina longipalpis (Diptera: Glossinidae) in Côte d'Ivoire. Mol. Ecol., 4: 245-249.

Solano P, Reifenberg JM, Amsler-Delafosse S, Kaboré I, Cuisance I, Duvallet G, 1996. Trypanosome characterization by polymerase chain reaction in Glossina palpalis Gambiensis and Glossina tachinoides from Burkina Faso. Medical and Veterinary Entomology, 10: 354-358.

Swallow BM, 2000. Impacts of trypanosomiasis on African agriculture, PAAT technical and scientific series, Volume 2. 52pp.

Trail JCM, Murray M, Sones K, Jibbo JMC, Darkin J, Light D, 1985. Boran cattle maintained by chemoprophylaxis under trypanosomiasis risk. Journal of Agricultural Science, 105: 147-166

Wilson ML, Bretsky PM, Cooper GH, Egberson, SH, Cartter ML, 1997. Spatial and temporal characteristics of animal infection and human contact. American Journal of Tropical Medicine and Hygiene, 57 (4): 457-463. 